\title{
Self-efficacy and antiretroviral therapy adherence among HIV positive pregnant women in South-West Nigeria: a mixed methods study
}

OLUWABUSAYO H. AREGBESOLA and IKEOLA A. ADEOYE*

Department of Epidemiology and Medical Statistics, Faculty of Public Health, College of Medicine, University of Ibadan, Ibadan, Nigeria

\begin{abstract}
Background: In Nigeria, an estimated 60,000 paediatric HIV infections occur annually mainly through motherto-child transmission. Adherence to antiretroviral therapy (ART) in pregnancy is crucial in preventing new paediatric HIV infections. We investigated HIV-treatment adherence self-efficacy and ART adherence among HIV-positive pregnant women in South-West Nigeria.

Methods: A mixed method approach was employed using a sequential explanatory strategy in which HIVpositive pregnant women were recruited from three facilities providing Prevention of Mother-to-Child Transmission (PMTCT) services. Self-efficacy and adherence were assessed using the HIV-Treatment Adherence Self-efficacy Scale and the Centre for Adherence Support Evaluation Index Tool, respectively. A focus group discussion and key informant interviews were used to explore barriers and motivating factors to ART adherence in pregnancy. Quantitative data were analysed using descriptive statistics and logistic regression at $5 \%$ significance level, while thematic content analysis was used to analyse qualitative data.

Results: A total of 126 women participated in the study. The mean age and mean gestational age of respondents were $32.7 \pm 4.58$ years and $24.4 \pm 7.41$ weeks, respectively. The prevalence of good adherence and HIV-treatment adherence self-efficacy were $70.6 \%$ and $26.2 \%$, respectively. Low self-efficacy $(\mathrm{OR}=0.2$, $95 \% \mathrm{Cl}=0.05$ 国 0.53, $\mathrm{p}<0.05$ ) was statistically associated with poor adherence. Planned pregnancy (OR=3.1, $95 \% \mathrm{Cl}=1.23-7.72, \mathrm{P}<0.05)$ increased the likelihood for ART adherence. Looking healthier and protecting unborn babies were motivators to adherence while stigmatization and negative spousal influences were barriers to adherence.

Conclusion: Low HIV-treatment adherence self-efficacy was related to poor adherence in pregnancy. Interventions aimed at improving adherence in pregnancy should also focus on HIV-treatment adherence self-efficacy.

Keywords: HIV/AIDS, antiretroviral therapy, adherence, self-efficacy, Nigeria
\end{abstract}

\section{Introduction}

Globally, mother-to-child transmission (MTCT) of the human immunodeficiency virus (HIV) infection is responsible for over $90 \%$ of more than two million paediatric HIV. The risk of transmission ranges from $25 \%$ to $48 \%$ in resource limited settings (UNAIDS, 2010). The prevention of mother-to-child transmission (PMTCT) of HIV is a strategy to reduce the risk of transmission from a mother to her baby by providing drugs, counselling and psychological support (NFMOH, 2010). However, low and middle income countries have challenges in access to PMTCT services (Nachega et al., 2012). SubSaharan Africa has 2.3 million out of the 2.5 million children living with HIV worldwide of which Nigeria contributes $14 \%$ of the total African burden of paediatric HIV (WHO, 2015). Although antiretroviral therapy (ART) is available as part of the PMTCT services, Nigeria still reports an unacceptably high incidence of HIV in infants (Oladokun et al., 2013). According to the UNAIDS (2012) report, an estimated 60,000 new HIV infection occurred among Nigerian infants. This makes Nigeria the country with the largest number of children acquiring HIV through MTCT.

The World Health Organization recommends ART as a key component of all effective PMTCT strategies (WHO, 2010). During and after pregnancy, ART is critical both for preserving maternal health and for the preventing of new infections in infants (Ayuo et al., 2013). However, adherence to prescribed ART among HIV infected pregnant women continues to be a major public health concern 
in both high and low income countries. Adherence is the extent to which a person uses a medication according to medical recommendations, inclusive of timing, dosing and consistency (Chaiyachati et al., 2014). Adherence rates above $95 \%$ are necessary in order to derive the greatest benefit from ART (WHO, 2015). ART should be initiated in all adults, adolescents, with pregnant and breast feeding women, and children with a diagnosis of HIV regardless of WHO clinical stage and regardless of CD4+ cell count as a priority (NFMOH, 2016). Conversely, poor adherence to antiretroviral drugs during pregnancy can lead to the development of viral resistance in the mother, a higher risk of MTCT as well as MTCT of resistant HIV strains (Ngarina et al., 2013). Therefore, adherence to antiretroviral drugs is important for HIV infected persons particularly pregnant women (Mirkuzie et al., 2011; Ekama et al., 2012; Ngarina et al., 2013; Boateng et al., 2013). Factors that affect ART adherence also affect PMTCT service uptake. Efforts to reduce the burden of HIV/AIDS in Nigeria by ensuring uptake and adherence have been challenging (Oladokun et al., 2013; Hodgson et al., 2014).

Self-efficacy has been identified as important in adherence to HIV treatment. HIV treatment adherence self-efficacy refers to patients' beliefs about their ability to exercise personal control regarding their HIV treatment. It has been recommended that self-efficacy must be considered in patients who are to initiate ART because it's highly predictive of adherence to ART (Adefolalu et al., 2014). Studies have reported the association between adherence self-efficacy and ART adherence in HIV patients such as adolescents, men and non-pregnant women (Adefolalu et al., 2014; Hodgson et al., 2014). However, fewer studies have investigated HIV treatment adherence self-efficacy among pregnant women in Sub-Saharan Africa (Bailey et al., 2014). Therefore, this study examined selfefficacy and ART adherence among women assessing PMTCT services in Ibadan, Oyo State in southwestern Nigeria.

\section{Materials and Methods}

\section{Study design and setting}

This was a cross-sectional study which employed a mixed method approach. The study was conducted in three PMTCT centres in Ibadan, the capital city of Oyo State. These were Adeoyo Maternity Hospital in Adeoyo, Our Lady of Apostles Catholic Hospital in Oluyoro, Oke-Ofa and Saint Mary's Catholic General Hospital in Eleta. The PMTCT facilities are supported by AIDS Prevention Initiative in Nigeria (APIN) through the United States President's Emergency Fund for AIDS Relief (PEPFAR). The Centres provide outpatient PMTCT services to HIV positive pregnant women, in addition to adult and paediatric HIV services.

\section{Study population, sample size and selection}

The study population consisted of HIV positive pregnant women who had registered for PMTCT services in any of the selected secondary health facilities. The eligibility criterion was the commencement of ART at least eight weeks prior to the study. HIV positive pregnant women who presented with any form of acute emergency were excluded from the study. The sample size was estimated using the sample size calculation for single proportions, at a precision of $5 \%$, and assuming a prevalence of ART adherence of $80.6 \%$ among pregnant women (Holstad et al., 2012). The minimum sample size obtained was 111. After adjusting for none response, 126 HIV positive women were enrolled into the quantitative aspect of the study. The women were sequentially recruited from the selected facilities on their clinic days.

In the qualitative study, 18 consenting HIV positive pregnant women were selected from Adeoyo Maternity Hospital using convenient sampling technique. Two focused group discussions (FGD) with nine participants each were conducted. Key Informant Interviews (KII) were conducted with five health care providers in different job positions (two ward assistants, a nurse, a monitoring 
and evaluation officer and the pharmacist focal person) at Saint Mary's Catholic General Hospital using an interview guide.

\section{Data collection}

The Centre for Adherence Support Evaluation (CASE) tool validated by Mannheimer et al. (2006) is a simple composite measure of self-reported ART that uses three standard measures of self-reported adherence. These are Self-reported frequency of 'difficulty taking HIV medications on time' , 'average number of days per week at least one dose of HIV medications was missed' and 'last time missed at least one dose of HIV medications' (Mannheimer et al., 2006). The HIV Treatment Adherence selfefficacy (HIV-ASES) was measured using the 12-item scale. Participants reported important treatment-related behaviours associated with adhering to their treatment regimen in the face of barriers by indicating their level of confidence from ' cannot do at all' (o point), ' moderately certain can do' (1 point) and ' completely certain can do' ( 2 points). The items were initially created for use in HIV behavioural trials which include an emphasis on adherence. Data collection took place between September 2015 and January 2016. The pre-tested interviewer-administered questionnaire contained information on socio-demographic, obstetric and HIV related characteristics, knowledge questions on HIV, PMTCT and ART, the CASE Index tool and questions adapted from the HIV-ASES. The questionnaire was translated into the Yoruba language and translated back to English to ensure correctness. Both versions of the questionnaire were available to the participants.

A focus group discussion (FGD) guide was used to explore the following thematic areas: HIV treatment adherence self-efficacy and factors associated with ART-adherence in pregnancy. An FGD guide, note pad and a digital audio recorder were used during the session located within one of the health facilities in which the pregnant women participated. The session was audio recorded and later transcribed for analysis. The healthcare providers participated in key informant interviews which sought to explore barriers and motivating factors to ART adherence in pregnancy.

\section{Data analysis}

The Statistical Package for Social Sciences (SPSS) version 16 was used to enter and analyse the quantitative data. Descriptive statistics was used to summarize the socio-demographic, obstetric, and HIV related characteristics. A score of $\leq 11$ in the CASE index tool was the cut-off for defining poor ART adherence as this score had the greatest association with viral load measures in validation analyses (Bailey et al., 2014). A score of $\leq 15$ indicated low HIV treatment adherence self-efficacy. Bivariate analysis was used to determine the factors associated with adherence during pregnancy. Chi-square test was used to summarize differences in proportion (prevalence of risk factors by sociodemographic variables). Binary logistic regression was used to adjust for confounding and determine factors statistically significantly associated with adherence. A p-value of less than 0.05 indicated statistical significance. Data obtained from the FGDs were transcribed verbatim. The transcripts were reviewed using the side noted and ideas noted.

\section{Ethical consideration}

Ethical approval was obtained from the Ethics Review Committee of the Oyo Ministry of Health. Participants were informed about the nature of the study and informed consent was obtained from all participants. All data acquired during the course of the research was kept confidential and anonymity assured. The participants had the right to withdraw from the study with no consequences of doing so. 


\section{Results}

\section{Characteristics of study participants}

A total of 126 HIV positive pregnant women were interviewed. The mean age and mean gestational age were of $32.7 \pm 4.58$ years and of 24.4 weeks \pm 7.41 weeks. One hundred and sixteen (92.1\%) of the women were married, $62.1 \%$ were Christians, $72.2 \%$ had at least secondary level of education and more than three-quarter (77\%) earned less than \$ 60 monthly. A total of 95 (75.4\%) were multigravida and reported no complications in previous pregnancies. Seventeen (13.5\%) women had not disclosed their HIV status to anybody and $67(.2 \%)$ had partners who were negative. All the women were on the Triple ARV drug Option B+ with 62 (49.2\%) women reporting the commencement of treatment before current pregnancy and 81 (64.3\%) having no previous PMTCT experience. Most of the women (95.2\%) had spousal support. Sixteen women accessing PMTCT services participated in the focus group discussion. They had a mean age of $34.5 \pm 5.1$ years, were currently married, had at least a primary education and had a mean gestational age of $26.9 \pm 7.8$ weeks.

Socio-demographic, obstetrics and HIV - related characteristics of the participants

\begin{tabular}{|c|c|c|c|}
\hline Characteristic & Response & Frequency (n) & Percentage \\
\hline \multirow[t]{3}{*}{ Age group (years) } & $20-29$ & 31 & 24.6 \\
\hline & $30-39$ & 83 & 65.9 \\
\hline & $\geq 40$ & 12 & $9 \cdot 5$ \\
\hline \multirow[t]{3}{*}{ Marital status } & Never married & 6 & 4.8 \\
\hline & Married & 116 & 92.1 \\
\hline & Separated/Divorced & 4 & 3.2 \\
\hline \multirow[t]{4}{*}{ Level of education } & None & 20 & $15 \cdot 9$ \\
\hline & Primary school & 15 & 11.9 \\
\hline & Secondary school & 63 & 50.0 \\
\hline & Tertiary school & 28 & 22.2 \\
\hline \multirow[t]{2}{*}{ Monthly income (US\$) } & $<60$ & 97 & 77.0 \\
\hline & $\geq 60$ & 29 & 23.0 \\
\hline \multirow[t]{2}{*}{ Gravidity } & Primigravida & 31 & 24.6 \\
\hline & Multigravida & 95 & 75.4 \\
\hline \multirow[t]{2}{*}{ Complications in previous pregnancies } & Yes & 28 & 22.2 \\
\hline & No & 98 & 77.8 \\
\hline \multirow[t]{3}{*}{ Gestational age (weeks) } & $<13$ & 11 & 8.7 \\
\hline & $13-28$ & 85 & 67.5 \\
\hline & $\geq 29$ & 30 & 23.8 \\
\hline \multirow[t]{4}{*}{ HIV status disclosure* } & Nobody & 17 & 13.5 \\
\hline & Husband/Partner & 88 & 69.8 \\
\hline & Family member & 47 & $37 \cdot 3$ \\
\hline & Friend & 7 & 5.6 \\
\hline \multirow[t]{3}{*}{ HIV status of husband/partner } & Negative & 67 & 53.2 \\
\hline & Positive & 16 & 12.7 \\
\hline & Unknown & 43 & 34.1 \\
\hline \multirow[t]{4}{*}{ Time of ART initiation } & Before pregnancy & 62 & 49.2 \\
\hline & $1^{\text {st }}$ Trimester & 22 & 17.5 \\
\hline & $2^{\text {nd }}$ Trimester & 32 & 25.4 \\
\hline & $3^{\text {rd }}$ Trimester & 10 & 7.9 \\
\hline \multirow[t]{2}{*}{ Previous PMTCT experience } & Yes & 45 & 35.7 \\
\hline & No & 81 & $64 \cdot 3$ \\
\hline
\end{tabular}

*Number of respondents greater than 126 due to multiple responses 


\section{Measures of HIV treatment adherence self-efficacy}

The proportion of study participants with high self-efficacy was $73.8 \%$ with a median HIV treatment adherence self-efficacy (HIV-ASES) score of 21 (IQR=15) out of a total of 24. Most of the study participants demonstrated high confidence in most of the domains related to their adherence to ART, particularly on the occurrence of side effects $103(81.7 \%)$ and integrating treatment with daily routine 105 (83.3\%). However, 54 (42.9\%) women reported self-efficacy was lowest on the use of medications in the presence of people unaware of their HIV status (Table 2).

Table 2 Responses to measures of HIV treatment adherence self-efficacy $(\mathrm{N}=126)$

\begin{tabular}{|c|c|c|c|}
\hline HIV adherence self-efficacy & $\begin{array}{l}\text { Cannot do at all } \\
\mathrm{n}(\%)\end{array}$ & $\begin{array}{l}\text { Moderately can do } \\
\mathrm{n}(\%)\end{array}$ & $\begin{array}{l}\text { Completely can do } \\
\mathrm{n}(\%)\end{array}$ \\
\hline $\begin{array}{l}\text { Stick to treatment even with side effects } \\
\text { interfering }\end{array}$ & $8(6.3)$ & $15(11.9)$ & $103(81.7)$ \\
\hline Integrate treatment into daily routine & $7(5.6)$ & $14(11.1)$ & $105(83.3)$ \\
\hline $\begin{array}{l}\text { Take medication inform of people unaware of } \\
\text { your status }\end{array}$ & 54 942.9) & $8(6.3)$ & $64(50.8)$ \\
\hline $\begin{array}{l}\text { Stick to treatment even when daily routine is } \\
\text { disrupted }\end{array}$ & $10(7.9)$ & $34(27.0)$ & $82(65.1)$ \\
\hline $\begin{array}{l}\text { Stick to treatment even when you are not } \\
\text { feeling well }\end{array}$ & $9(7.1)$ & $29(23.0)$ & $88(69.8)$ \\
\hline $\begin{array}{l}\text { Stick to treatment even if it means changing } \\
\text { eating habits }\end{array}$ & $8(6.3)$ & $38(30.2)$ & $80(63.5)$ \\
\hline $\begin{array}{l}\text { Continue treatment even if interferes with } \\
\text { daily activities }\end{array}$ & $8(6.3)$ & $34(27.0)$ & $84(66.7)$ \\
\hline $\begin{array}{l}\text { Continue treatment plan from physician even } \\
\text { T-cells drops }\end{array}$ & $8(6.3)$ & $42(33.3)$ & $76(60.3)$ \\
\hline $\begin{array}{l}\text { Continue treatment even when discouraged } \\
\text { about health }\end{array}$ & $6(4.8)$ & $28(22.2)$ & $92(73.0)$ \\
\hline $\begin{array}{l}\text { Continue treatment even when getting to } \\
\text { clinic is a hassle }\end{array}$ & $7(5.6)$ & $29(23.0)$ & $90(71.4)$ \\
\hline $\begin{array}{l}\text { Continue treatment if close people say it is } \\
\text { not doing good }\end{array}$ & $10(7.9)$ & $30(23.8)$ & $86(68.3)$ \\
\hline $\begin{array}{l}\text { Positive about treatment even without health } \\
\text { improvement }\end{array}$ & $10(7.9)$ & $34(27.0)$ & 82965.10 \\
\hline
\end{tabular}

The narrative from the FGD supported self-efficacy on adherence to medications: "I know that I must keep taking the drug so that the drug will prevent me from dying from AIDS" (31 years old, housewife, primary education). I was told that I must keep taking the drug even though there are side effects, I will get used to it (45 years old, trader, primary education).

\section{Prevalence and reasons for adherence in pregnancy}

The level of adherence was good in majority of the HIV positive pregnant women 89 (70.6\%). Notably, 20 (15.9\%) reported missing at least one dose in the week prior to the study, while $46.0 \%$ had never missed a dose. This finding was supported by the key informants who stated that adherence counselling and simplified drug regimen were responsible for the high ART adherence and very low rate of default. "If you consider the PMTCT adherence percentage in this centre, it is between 95\% and 97\%. As far as the pharmacy is concerned, you look at the appointment date, check the number of pills left in their pill container and also look at the countenance of the patient and from there, you can infer if the patient is complying or not. The default rate at the end of the day is negligible, not more than $3 \%$ to $5 \%$ " (Key Informant, Pharmacist Focal Person). 
The most commonly reported motivation for good ART adherence were the need to stay healthy (84.9\%) and the protection of the unborn child (76.9\%). On the other hand, the barriers to ART adherence were forgetfulness (19.0\%), faith in spiritual healing (16.7\%), hiding their HIV identity (37.3\%). These findings were further supported by the qualitative findings. Most key informants stated that the motivating factors to ART adherence included free treatment, good self-efficacy, adequate information from adherence counsellors, support from HIV support group meetings and the desire to protect the unborn baby. This is shown in an excerpt: "The treatment is free so the women don't have any problem with adherence even though they can decide to give birth in another facility. They usually have support group meetings every last Friday of the month" (Key Informant, Monitoring and Evaluation Officer). "When we give them the appointment card, it has the date for the next visit. The other thing that reminds them is the number of drugs they have left since we don't give them excess drugs, we give them for the month. When it remains one or two, they will look at the card and know that their appointment is close so, they can call the monitoring and evaluation officer. "Our numbers are on their appointment cards" (Key Informant, Pharmacist Focal Person).

Table 3: Factors associated with ART adherence among respondents with unadjusted and adjusted odds ratio (OR) at $95 \%$ confidence interval

\begin{tabular}{|c|c|c|c|c|c|}
\hline Variable & Response & Unadjusted OR & P-value & Adjusted OR & P-value \\
\hline \multirow[t]{2}{*}{ Monthly Income (US\$) } & $<20,000$ & 1 & & 1 & \\
\hline & $\geq 20,000$ & $0.4(0.15-1.21)$ & 0.109 & $2.1(0.577-7.34)$ & 0.266 \\
\hline \multirow[t]{2}{*}{ Gravidity } & Primigravida (ref) & 1 & & & \\
\hline & Multigravida & $0.9(0.40-2.39)$ & 0.963 & $1.5(0.45-4.71)$ & 0.533 \\
\hline \multirow[t]{2}{*}{ Planned pregnancy } & No (ref) & 1 & & 1 & \\
\hline & Yes & $3.191 .23-7.72)$ & $0.016 *$ & $6.4(1.96-20.70)$ & $0.002 *$ \\
\hline \multirow[t]{2}{*}{ Current gestational age } & $\leq 20$ weeks (ref) & 1 & & 1 & \\
\hline & $>20$ weeks & $0.3(0.12-0.97)$ & $0.043^{*}$ & $0.3(0.07-0.95)$ & $0.042 *$ \\
\hline \multirow{2}{*}{$\begin{array}{l}\text { Knowledge of modes } \\
\text { transmission of HIV }\end{array}$} & Poor (ref) & 1 & & 1 & \\
\hline & Good & $4.8(1.84-12.63)$ & $0.001 *$ & $3.2(0.96-10.62)$ & 0.059 \\
\hline \multirow{2}{*}{$\begin{array}{l}\text { HIV status disclosure } \\
\text { husband/partner }\end{array}$} & No (ref) & 1 & & 1 & \\
\hline & Yes & $2.3(1.03-5.21)$ & $0.042^{*}$ & $2.1(0.78-5.68)$ & 0.141 \\
\hline \multirow[t]{2}{*}{ Self-efficacy score } & >15 (high) (ref) & 1 & & 1 & \\
\hline & $\leq 15$ (low) & $0.2(0.75-142)$ & $0.001 *$ & $0.1(0.05-0.41)$ & $0.001 *$ \\
\hline
\end{tabular}

*Statistically significant at $\mathrm{P}<0.05$

Barriers to ART use were body weaknesses, the commencement of treatment, fear of stigmatization, lack of time and long distances to HIV support. Examples of side effects mentioned were: "I did not use it at first because it made me feel weak. God is the merciful One, He will help us' (45, trader, primary education). "You must use it well. I had tuberculosis and treated it first so, the cough stopped. When I took ARV drug for the first five days, it was difficult because it was my first time of using it but I got used to it" (45, trader, primary education). Examples of fear of stigma stated by interviewees were: "I pour my drugs into a plastic bag and burn the container the next day when I cook. Through this, no one will know I have HIV because people are funny, they can start telling other people" (32 years old, hair-dresser, secondary education). "My family advised me to hide my drugs so that people will not find out. Stigmatizing people living with HIV should not continue in other places. People should be more informed of HIV/AIDS so as to accommodate us" (32 years old, artisan, secondary education). An example of long distance to health facility as a barrier to ART use: "My house is too far from the meeting place. Besides, I cannot leave my job during the week on a Monday for that matter, I am a civil servant" (30 years old, civil servant, tertiary education). 


\section{Factors associated with ART adherence during pregnancy}

The proportion of respondents with poor adherence was 37 (29.4\%). Mean CASE score was 12.9 \pm 3.42 . After adjusting for confounders, current gestational age, planned pregnancy and HIV treatment adherence self-efficacy remained significantly associated with ART adherence (Table 3). Women with current gestational age of above 20 weeks were significantly three times less likely to adhere to ART than women with gestational age of 20 weeks or less ( $\mathrm{OR}=0.3,95 \% \mathrm{Cl}=0.07-0.95, \mathrm{P}<0.05)$. Women with low HIV treatment adherence self-efficacy were ten times less likely to adhere to ART than women with high HIV treatment adherence self-efficacy and this was statistically significant (OR=0.1, $95 \% \mathrm{Cl}=0.05-0.41, \mathrm{P}<0.05)$.

\section{Discussion}

This study investigated self-efficacy and ART adherence among HIV positive pregnant women assessing PMTCT services in Ibadan, South-West Nigeria. Our study provides evidence on the influence of self-efficacy on ART adherence among HIV positive pregnant women in Nigeria. Whereas HIV treatment adherence self-efficacy have commonly been measured using self-reports, we used a validated tool - the 12-item HIV treatment adherence self-efficacy scale (Johnson et al., 2007). Our study participants demonstrated the highest self-efficacy at being able to integrate their ART drugs into their daily routine and continuing their treatment in spite of experiencing side effects. On the other hand, the least level of efficacy was reported in taking their medications in the presence of people that were unaware of their HIV status. The qualitative findings supported this position as the desire for secrecy and fear of stigmatization could sometimes prevent women from taking their drugs as they ought to. A systematic review of individual and contextual factors affecting ART initiation, adherence, and retention for HIV-infected pregnant and postpartum women, reported that stigma or anticipated stigma are important hindrances to both the initiation and adherence to ART among HIV positive pregnant women in Africa (Hodgson et al., 2014).

We found that women with low HIV treatment adherence self-efficacy were more likely to report poor adherence to ART. This agrees with previous studies which have shown that self-efficacy is a predictor of ART adherence behaviour (Johnson et al., 2007; Nokes et al., 2012; Reif et al., 2013; Adefolalu et al., 2014; Bailey et al., 2014). Hence it is recommended that self-efficacy should be assessed in those to commence ART because it's a strong predictor for ART adherence (Adefolalu et al., 2014). Similarly, healthcare providers and counsellors (should work with patients in order to improve their self-efficacy with the aim of promoting ART treatment adherence (Nokes et al., 2012). In addition, social network and social support systems can leverage on HIV treatment adherence selfefficacy to enhance PMTCT services. For instance, spouses of HIV positive could encourage and remind them to take their drugs thereby facilitating ART adherence. Johnson et al. (2012), in a study in the USA reported that partners with higher commitment to their relationship, positive beliefs of treatment efficacy and less concern about side effects, were associated with the patient's better adherence. This implies that PMTCT programmes should strongly enlist spousal support and seek to address their treatment efficacy in order to facilitate adherence to ART treatment. Spousal support needs to begin with the disclosure of the HIV status to the spouse.

Non-disclosure of HIV status to partner has been reported as an important barrier to PMTCT because of its association with the fear of rejection and domestic violence (Ekama et al., 2012; Ngarina et al., 2013). Contrarily, a high proportion of our study participants reported disclosure to their husbands also, as women who disclosed their HIV status to their spouses had twice the odds of good adherence compared to those who did not disclose. This was supported by the qualitative data which showed that the women were motivated to adhere to ART when reminded to take their drug 
or emotionally supported by their spouses and significant others. The good adherence to ART observed in this $r$ study may be attributable to maternal concerns about preventing HIV infection in their unborn child. Previous studies have also reported good ART adherence by mothers for the similar reasons (Kuonza et al., 2010; Mepham et al., 2011; Ekama et al., 2012; Ayuo et al., 2013; Bailey et al., 2014). Findings from the qualitative data revealed that the desire to protect their unborn babies from HIV, looking healthier and living longer, and previous PMTCT experience could be responsible for their ART adherence. Similar findings studies have also reported high ART adherence by pregnant women in recent years (Ekama et al., 2012; Bailey et al., 2014). Hence, these issues need to be emphasized at programs aimed at encouraging mothers to adhere to ART. Women with a good knowledge of the modes of HIV transmission were about five times more likely to adhere to ART than those with poor knowledge. This may indicate a good knowledge about HIV/AIDS due to various awareness campaigns. In addition, women who planned their current pregnancy were more likely to have good ART adherence.

Poor adherence to ART is a major challenge in the PMTCT of HIV. Despite an overall high level of adherence in this study, a quarter reported missing at least one dose the week preceding the interview. This is similar to the finding among HIV positive pregnant women in Ukraine in which a third of women in the survey reported missing at least a dose in pregnancy the preceding four weeks before the survey (Bailey et al., 2014). Reasons reported by the women included sleeping off, forgetting to take the drug and belief in spiritual healing, through prayer and fasting. The public health implication is that efforts to reduce the number of children acquiring HIV through MTCT in Nigeria still needs to be intensified in order to prevent new paediatric HIV infections. HIV treatment adherence self-efficacy was associated with ART adherence and it is crucial for adherence-related behaviour. High Antiretroviral therapy adherence was high and was attributed to the desire to stay healthy and to protect the unborn child. Programs that aim to improve ART adherence in pregnancy should address self-efficacy issues and incorporate them into behaviour change communication in women assessing treatment and care. ART scale-up efforts should also include addressing misconceptions, stigmatization and HIV treatment adherence self-efficacy.

There are some limitations in this study. Even though use used the CASE adherence index tool, it is still subject to social desirability bias. Secondly, recall bias regarding ARV drug use may have occurred thus, adherence may have been over estimated. Despite these, this study provides useful information on HIV treatment adherence self-efficacy as an important factor in ART adherence.

In conclusion, low HIV-treatment adherence self-efficacy is related to poor adherence in pregnancy. Interventions aimed at improving adherence in pregnancy should also focus on HIVtreatment adherence self-efficacy.

\section{Conflict of interest}

None declared

\section{Authors' contribution}

OHA, IAA designed the study. OHA conducted the study. OHA, IAA performed statistical analysis and data interpretation. OHA wrote the first draft of the manuscript. Both authors read and approved the final version of the manuscript. 


\section{Acknowledgements}

The authors would like to express their gratitude to the coordinators of the PMTCT programme in the study sites. The contributions of the research assistants and study participants are acknowledged.

\section{References}

Adefolalu, A., Nkosi, Z., Olorunju, S. \& Masemola, P. (2014) Self-efficacy, medication beliefs and adherence to antiretroviral therapy by patients attending a health facility in Pretoria. South African Family Practice 56:281-285.

Ayuo, P., Musick, B., Liu, H., Braitstein, P., Nyandiko, W., Otieno-Nyunya, B., Gardner, A. \& WoolsKaloustian, K. (2013) Frequency and factors associated with adherence to and completion of combination antiretroviral therapy for prevention of mother to child transmission in western Kenya. Journal of the International AIDS Society 16:17994.

Bailey, H., Thorne, C., Malyuta, R., Townsend, C.L., Semenenko, I. \& Cortina-Borja, M. (2014) Adherence to antiretroviral therapy during pregnancy and the first year postpartum among HIV-positive women in Ukraine. BMC Public Health 14:993.

Boateng, D., Kwapong, G.D. \& Agyei-Baffour, P. (2013) Knowledge, perception about antiretroviral therapy (ART) and prevention of mother to child transmission (PMTCT) and adherence to ART among HIV positive women in Ashanti Region, Ghana: a cross sectional study. BMC Women's Health 13:2.

Chaiyachati, K.H., Ogbuoji, O., Price, M., Suthar, A.B., Negussie, E.K. \& Bärnighausen, T. (2014) Intervention to improve adherence to antiretroviral therapy: a rapid systematic review. AIDS 28:S187-S207.

Ekama, S.O., Herbertson, E.C., Addeh, E.J., Gab-Okafor, C.V., Onwujekwe, D.I., Tayo, F. \& Ezechi, O.C (2012) Pattern and Determinants of Antiretroviral Drug Adherence among Nigerian Pregnant Women. Journal of Pregnancy Article ID 851810, 6 pages doi:10.1155/2012/85181.

Hodgson, I., Plummer, M.L., Konopka, S.N., Colvin, C.J., Jonas, E., Albertini, J., Amzel, A. \& Fogg, K.P. (2014) A Systematic Review of Individual and Contextual Factors Affecting ART Initiation, Adherence, and Retention for HIV-Infected Pregnant and Postpartum Women. PLOS ONE 9(11):e111421.

Holstad, M.M., Essien, J.E., Ekong, E., Higgins, M., Teplinskiy, I. \& Adewuyi, M.F. (2012) Motivational Groups Support Adherence to Antiretroviral Therapy Adherence and use of Risk Reduction Behaviours in HIV Positive Nigerian Women: A Pilot Study. African Journal of Reproductive Health 16: 14-17.

Johnson, M.O., Dilworth, S.E., Taylor, J.M., Darbes, L.A., Comfort, M.L. \& Neilands, T.B. (2012) Primary Relationships, HIV Treatment Adherence, and Virologic Control. AIDS Behave 16: 1511 1521.

Johnson, M.O., Neilands, T.B., Dilworth, S.E., Morin, S.F., Remien, R.H. \& Chesney, M.A. (2007) The Role of self-Efficacy in HIV Treatment Adherence: Validation of the HIV Treatment Adherence Self-Efficacy Scale (HIV-ASES). Journal of Behavioral Medicine 30:359-70.

Kuonza, L.R., Tshuma, C.D., Shambira, G.N. \& Tshimanga, M. (2010) Non-adherence to the single dose nevirapine regimen for the prevention of mother-to-child transmission of HIV in Bindura town, Zimbabwe: a cross-sectional analytic study. BMC Public Health 10:218.

Mannheimer, S.B., Mukherjee, R., Hirschhorn, L.R., Dougherty, J., Celano, S.A., Ciccarone, D., Graham, K.K., Mantell, J.E., Mundy, L.M., Eldred, L., Botsko, M. \& Finkelstein, R. (2006) The CASE adherence index: A novel method for measuring adherence to antiretroviral therapy. AIDS Care 18: 853- 861. 
Mepham, S., Zondi, Z., Mbuyazi, A., Mkhwanazi, N. \& Newell, M.L. (2011) Challenges in PMTCT antiretroviral adherence in northern KwaZulu-Natal, South Africa. AIDS Care: Psychological and Socio-medical Aspects of AIDS/HIV 23: 741-747.

Mirkuzie, A.H., Hinderaker, S.G., Sisay, M.M., Moland, K.M. \& Mørkve, O. (2011) Current status of medication adherence and infant follow up in the prevention of mother to child HIV transmission programme in Addis Ababa: a cohort study. Journal of the International AIDS Society 14:50.

Nachega, J.B., Uthman, O.A., Anderson, J., Peltzer, K., Wampold, S., Cotton, M.F., Mills, E.J., Ho, Y.S., Stringer, J.S.A., Mclyntre, J.A. \& Mofenson, L.M. (2012) Adherence to antiretroviral therapy during and after pregnancy in low-income, middle-income and high-income countries: a systematic review and meta-analysis. AIDS 26:2039-2052.

Ngarina, M., Popenoe, R., Kilewo, C., Biberfeld, G. \& Ekstrom, A.M. (2013) Reasons for poor adherence to antiretroviral therapy postnatally in HIV-1 infected women treated for their own health: experiences from the Mitra Plus study in Tanzania. BMC Public Health 13:450.

$\mathrm{NFMOH}$ (2010) National guidelines for prevention of mother-to-child transmission of HIV. Nigeria Federal Ministry of Health Available at http://www.emtct-iatt.org/wpcontent/upload/2013/04/Nigeria_National-PMTCT-Guidelines_2010.pdf.

NFMOH (2016) National Guidelines for HIV prevention, treatment and Care. Nigeria Federal Ministry of Health Available at https://aidsfree.usaid.gov.

Nokes, K., Johnson, M.O., Webel, A., Rose, C.D., Phillips, J.C., Sullivan, K., Tyer-Viola, L., RiveroMéndez, M., Nicholas, P., Kemppainen, J., Sefcik, E., Chen, W., Brion, J., Eller, L., Kirksey, K., Wantland, D., Portillo, C., Corless, I.B., Voss, J., lipinge, S., Spellmann, M. \& Holzemer, W.L. (2012) Focus on Increasing Treatment Self-Efficacy to Improve Human Immunodeficiency Virus Treatment Adherence. Journal of Nursing Scholarship 44: 403? 410.

Oladokun, R.E., Ige, O. \& Osinusi, K. (2013) Gaps in preventing mother to child transmission (PMTCT) and human immune deficiency virus (HIV) exposure among infants in a Nigerian City: Implications for health systems strengthening. Journal of AIDS and HIV Research 5: 254-259.

Reif, S., Proeschold-Bell, R.J., Yao, J., LeGrand, S., Uehara, A., Asiimwe, E. \& Quinlivan, E.B. (2013) Three types of self-efficacy associated with medication adherence in patients with cooccurring HIV and substance use disorders, but only when mood disorders are present. Journal of Multidisciplinary Healthcare 6 229-237.

UNAIDS (2010) Global Report: UNAIDS report on the global AIDS epidemic 2010. Available at http://www.unaids.org/globalreport/documents/20101123GlobalReportfullen.pdf.

UNAIDS (2012) Every minute, a young woman is infected with HIV. Geneva, Switzerland: Joint United Nations Program on HIV/AIDS (UNAIDS). Retrieved July 30, 2015, from http://www.unaids.org/en/resources/infographics/20120608gendereveryminute/.

WHO (2015) PMTCT strategic vision 2010-2015: Preventing mother-to-child transmission of HIV to reach the UNGASS and Millennium Development Goals. Available at http://who.int/hiv/pub/mtct/strategic_vision.pdf.

WHO (2010) Antiretroviral drugs for treating pregnant women and preventing HIV infection in their infants: Recommendations for a public health approach. Geneva: World Health Organization. Available at http://who.int/hiv/pub/guidelines/pmtctguidelines3.pdf. 